\title{
Acute Moderate Normovolemic Hemodilution (ANH) in Major Elective Orthopaedic Surgeries- A Prospective Study
}

\author{
Authors \\ Satish Logidasan ${ }^{1}$, Kanimozhi Rathinasamy ${ }^{2}$, Gowrikshankar Anjineyan ${ }^{3}$ \\ ${ }^{1,2,3}$ Department of Anesthesiology, Govt Stanley Medical College, TN- 600001, India \\ Corresponding Author \\ Satish Logidasan \\ Department of Anesthesiology, Govt Stanley Medical College, TN- 600001, India
}

\begin{abstract}
:
Background: The adverse effects of blood transfusion, the cost factor and its shortage has necessitated the medical fraternity to evolve new strategies to overcome these, as limiting factors for surgery.ANH is one of the many options clinicians may use to minimize perioperative exposure to allogeneic blood products

Aim: Aim of the study is to study the efficacy of moderate acute normovolemic haemodilution in patients undergoing elective major orthopaedic surgeries with special references to the complications and its technical difficulties.

Materials and Methods: After obtaining approval of ethics committee and informed consents of the patient, 25 patients posted to undergo major orthopaedic elective surgeries were drafted into the study and ANH was performed. Mean change in Heart rate, blood pressure, oxygen saturation, bleeding time, clotting time, platelet count, haemoglobin, potassium were studied in the predilution and post dilution period. Cost factor and time factor were also analysed.

Conclusion: We conclude that moderate ANH is a safe, effective procedure that can be done with routine monitoring. This method is cost effective, the technical difficulties and complications are very minimal when compared to benefits.

Key words: Blood transfusion, Acute normovolemic hemodilution.
\end{abstract}

\section{Introduction}

ANH is a single term for a broad therapeutic initiative that involves simultaneously removing the patient's blood and repolarizing it with a non-blood product. By producing a considerable decrease in the erythrocyte mass and, thus, a decrease in the net erythrocyte loss, ANH decreases subsequent need for blood products.ANH entails are intentional decrease of hemoglobin concentration by withdrawal of a calculated volume of the patient's blood, after anesthetic induction or before the critical phases of surgery are started, and simultaneous replacement with a cell-free substitute to maintain a near-normal blood volume. The rationale for the use of $\mathrm{ANH}$ as a method for blood conservation is that if intraoperative blood loss is relatively constant, the loss of blood constituents, especially RBCs, would be reduced if the blood is diluted by a plasma expander. 


\section{Materials and Methods}

After obtaining approval of ethics committee and informed consents of the patient, 25 patients posted to undergo major orthopaedic elective surgeries were drafted into the study. Patients of age $20-50$ yrs ASA PS I $\mathrm{Hb}>10$ gms $\% \mathrm{PCV}>30 \%$, were included. Anaemia $\mathrm{Hb}<10 \mathrm{~g}$, Impaired Renal Function Impaired Pulmonary function Impaired Hepatic Function Impaired Cardiac function Untreated hypertension Coagulation disorders. Hypoalbunimea Hemoglobinopathy Patients with $\beta$ blockers were excluded.

$\mathrm{Hb} \%$ Total count, PCV \%Differential Count, Erythrocyte sedimentation rate, Platelet count, Blood urea, Blood Sugar, Sr. Creatinine, Sr. Electrolytes $\mathrm{Na}$, K, Bleeding time, Clotting time, Blood grouping \& Rh typing Urine microscopy, Chest xray and ECG were done.

Estimation of Blood Volume to be Drawn Duringacute Normovolemic Hemodilution

Estimated Blood Volume X HCTinitial - HCTfinal

Average HCT

\section{Estimated Blood Volume}

\begin{tabular}{|l|c|c|}
\hline Body Build & Adult Male $(\mathrm{mL} / \mathrm{Kg})$ & Adult Female $(\mathrm{mL} / \mathrm{Kg})$ \\
\hline Muscular & 75 & 70 \\
\hline Average & 70 & 65 \\
\hline Thin & 65 & 60 \\
\hline Obese & 60 & 55 \\
\hline
\end{tabular}

(Estimated Blood Volume $=$ Male $75 \mathrm{ml} / \mathrm{kg}$, female $70 \mathrm{ml} / \mathrm{kg}$ )

Premedication: Inj. Pentazocine I.M. 0.5mg / Kg.Inj. Glycopyrrolate I.M. 0.2mg Inj. Midazolam I.M. $0.05 \mathrm{mg} / \mathrm{Kg}$ was given. ECG, Pulse Oximeter, NIBP urinary Bladder Catheterisation done.All baselines values are recorded

\section{Pre Procedural Preparation}

ECG, Pulse Oximeter, NIBP were monitored. Urinary Bladder Catheterisation. All baselines values are recorded.

Two 16G Venflon cannula started ascetically, one on a big forearm via and the other Venflonc annulated into the external jugular vein. The cannulas are connected to colloid (gelofusine) and crystalloid (NS, RL) respectively.

\section{Collection of Blood}

- Blood was collected from the antecubital vein opposite to the upper limb, in which the intravenous fluids on flow.

- Blood volume to be collected was based on the calculation already performed using the formula, to perform moderate acute normovolemic haemodilution to achieve a target PCV of $28 \%$.

- Blood was collected onto the collapsible disposable blood bags of $450 \mathrm{~m} /$ volume with CPD-A $63 \mathrm{ml}$ as a preservative.

- Each $1 \mathrm{ml}$ of blood removed was replaced by $3 \mathrm{ml}$ of crystalloid (or) $1 \mathrm{ml}$ of gelofusine (colloid) simultaneously to achieve an appropriate blood pressure, to provide hemodilution and adequate tissue oxygenation.

- In the total volume of blood to be removed, the first half volume of blood removal was replaced volume / volume by gelofusine and second half volume of blood removed was replaced by (1:3) crystalloids (RL, NS, DNS).

- Blood bags were manually agitated intermittently during removal of the blood.

- Blood bags were weighed in a weighing machine to achieve a target volume.

- All vital signs were monitored during the process of haemodilution.

- Blood bags as they were collected they are labeled in the serial order of collection along with name, age, sex, IP No, Date, time of collection and kept in an aluminium bag for maintaining at near normal to the patients body temperature.

- Blood bags were kept in the theatre itself and care is taken that no one taken it outside the theatre complex.

- Blood samples are drawn for Hb PCV and sent for estimation.

- Anesthetic technique was standised to general anaesthesia with controlled ventilation.

- After the hemodynamic variables are stable. Patients are preoxygenated for $3 \mathrm{mts}$ and they were induced with $2.5 \% \quad$ Inj. 
Thiopentone sodium $(5 \mathrm{mg} / \mathrm{Kg})$ I.V. and intubated with Inj. Suxamethonium $2 \mathrm{mg} /$ $\mathrm{Kg}$ I.V. Appropriate size PVC Cuffed tubes were selected and intubated orotracheally. Bilateral air entry checked and the tubes were fixed. Anesthesia was maintained with Nitrous oxide / Oxygen 4/2 liters and Halothane $0.5 \%$ intermittently. Inj. Pancuronium is used to facilitate. Intermittent positive pressure ventilation. At the end of the procedure patient was reversed with Inj. Neostigmine $50 \mathrm{mcg} / \mathrm{kg}$ and Inj. Atropine $20 \mathrm{mcg} / \mathrm{kg}$. slow I.V.

- Intra operative fluid management included RL, NS, DNS, Gefofusine depending on the surgical blood loss with the aim of maintaining stable hemodynamics.

- Intra operative vital parameters are recorded. Blood losses was measured from - Swabs, Pads, drapes, Suction bottles.

- After achieving near complete hemostasis at the end of surgery (or) if blood loss exceeded $15-20 \%$ blood volume with unstable hemodynamics, collected blood was given in the reverse order of collection.

- If the surgical loss is massive and if it could not even be managed by the collected blood, then bank blood was ordered.

- All patients are followed up till discharge. They are examined for respiratory infection, delayed wound healing and any other complication and the same was documented.

\section{Observations}

Age of the patients were comparable. 24 male patients and 1 female were included. Average weight was $70 \mathrm{~kg}$ for all the patients.

Haemodynamic Parameters at Various Stages of Acute Normovolemic Hemodilution

\begin{tabular}{|l|c|c|c|c|}
\hline $\begin{array}{l}\text { Mean } \\
+ \text { SD }\end{array}$ & $\begin{array}{c}\text { Pre } \\
\text { Haemodilution }\end{array}$ & $\begin{array}{c}\text { Post } \\
\text { Haemodilution }\end{array}$ & $\begin{array}{c}\text { Pre } \\
\text { Transfusion }\end{array}$ & $\begin{array}{c}\text { Post } \\
\text { Transfusion }\end{array}$ \\
\hline HR & $84+6$ & $90+7$ & $92+8$ & $92+11$ \\
\hline SBP & $125+10$ & $128+9$ & $124+9$ & $127+8$ \\
\hline DBP & $77+6$ & $78+6$ & $786+5$ & $78+5$ \\
\hline MAP & $93.3+6.6$ & $94.7+6.5$ & $91.8+5.9$ & $94.2+5.9$ \\
\hline
\end{tabular}

TABLE 27

Complications
\begin{tabular}{|l|c|c|c|c|}
\hline Mean + SD & $\begin{array}{c}\text { Pre } \\
\text { Haemodilution }\end{array}$ & $\begin{array}{c}\text { Post } \\
\text { Haemodilution }\end{array}$ & $\begin{array}{c}\text { Pre } \\
\text { Transfusion }\end{array}$ & $\begin{array}{c}\text { Post } \\
\text { Transfusion }\end{array}$ \\
\hline Arrhythmias & Nil & Nil & Nil & Nil \\
\hline $\begin{array}{l}\text { Conjunctival } \\
\text { Oedema }\end{array}$ & Nil & Nil & Nil & $8 / 25$ \\
\hline $\begin{array}{l}\text { Pulmonary } \\
\text { Oedema }\end{array}$ & Nil & Nil & Nil & Nil \\
\hline Hypotension & Nil & Nil & $2 / 25$ & Nil \\
\hline $\begin{array}{l}\text { ST Segment } \\
\text { Changes }\end{array}$ & Nil & Nil & Nil & Nil \\
\hline Anxiety & $6 / 25$ & Nil & Nil & Nil \\
\hline Shivering & Nil & $8 / 25$ & Nil & Nil \\
\hline
\end{tabular}

\section{Results}

In our study the mean heart rate changes in the prehemodilution vs post hemodilution period, pre hemodilution vs pretransfusion period, prehemodilution vs post transfusion period were $6,8,9$ beats/min respectively and not statistically significant.

The MAP in the prehemodilution, post hemodilution, pre transfusion and post transfusion were $93.3+6.6 \mathrm{mmHg}, 94.27+6.5,91.8+5.994 .2+$ $5.9 \mathrm{mmHg}$ respectively and the changes were statistically insignificant.

The mean bleeding time in the pre hemodilution, post hemodilution, pretransfusion and post transfusion were $2.32+0.64,2.94+0.62,3.26+0.62$ and $2.96+0.56$ minutes respectively and the changes statistically insignificant.

The mean clotting time in the pre hemodilution, post hemodilution, pretransfusion and post transfusion were $4.22+0.79,4.83+0.89,5.17+$ 0.82 and $4.78+0.83$ minutes respectively and the changes were statistically insignificant.

The mean platelet count in the pre hemodilution, post hemodilution, pretransfusion and post transfusion were $2.84+0.44,2.03+0.41,1.77+0.43$ and $2.39+0.53$ lakhs/cumm respectively. The changes were statisticallt insignificant.

The mean haemoglobin in the pre hemodilution, post hemodilution, pretransfusion and post transfusion were $12.5+0.5,9.4+0.5,8+0.8$ and $10.5+1 \mathrm{gm} / \mathrm{dl}$ respectively.

The mean potassium ions in the pre hemodilution, post hemodilution, pretransfusion and post transfusion were $3.7+0.2,3.7+0.2,4.1+0.2$ and $4+0.2 \mathrm{mEq} / \mathrm{l}$ respectively. The changes were statistically significant. 
In our study the average blood collected was $1218 \mathrm{ml}$, colloid used was $640 \mathrm{ml}$, two $16 \mathrm{G}$ venflon and $450 \mathrm{ml}$ blood bags were used per patient. Total cost was 520.12 per patient.

The average blood volume collected was $1218 \mathrm{ml} /$ patient and it took 61 minutes for hemodilution and for collecting 1 unit of $450 \mathrm{ml}$ blood the time taken is 22.5 minutes. the process increased OT occupancy time by 60 minutes.

\section{Discussion}

The blood product returned to the patient contains in ANH has functional red cells, clotting proteins, and platelets. The 2,3 DPG levels remain well within normal levels regardless of the duration of ANH. Provides a cost effective blood conservation technique. ANH leads to improved tissue perfusion and oxygen delivery, which may be most important in patients with peripheral vascular and cerebrovascular disease. Some persons with religious objections agree to $\mathrm{ANH}$ as long as the blood is maintained in a closed-circuit system. The blood is readily available, free of the dangers of transfusion-transmitted disease, hemolytic and allergic reactions, and immunomodulatory effects.

Indications for acute normovolemic hemodilution is preoperative hematocrit must be $>34 \%$ and any type of surgery associated with significant blood loss.

The risk/benefit ratio or acute normovolemic hemodilution (ANH) must be determined on an individual basis by the medical specialists involved with the patient's care. Most of the contraindications listed below are relative, not absolute. Anemia is the major contraindication. ANH is usually inappropriate when the $\mathrm{Hb}$ is $\langle 10 \mathrm{~g}$ per $\mathrm{dL}$. Patients with impaired renal function who cannot excrete large amounts of infused fluid.ANH is usually precluded when an increase in cardiac output, the primary compensatory mechanism, is neither possible nor desirable; e.g. patients with coronary artery disease or aortic stenosis who are undergoing noncardiac surgery. Clinically evident limitations of cardiac or pulmonary function, untreated hypertension, and coagulation disorders.
A study of intra operative haemodilution and autotransfusion was carried out in patients undergoing major elective surgery to determine the safety of the procedure, amount of homologous blood saved and effect of hemodilution on the clinical status of the patient ${ }^{1}$. They concluded that the method was found to be safe and requirement of homologous blood was reduced by another $90 \%$.

The stress response of acute hemodilution in patients subjected to radical cystectomy (40 adult male patients were allowed into two groups, 20 in awake group and the other 20 patients in the anaesthetized group were studied ${ }^{2}$. The hemodynamic, hematological, biochemical and hormonal variable were taken into consideration. He concluded ANH in this magnitude is not a stress producing technique when performed in an awake patient and is not associated with significant changes in measured serum stress hormones $\mathrm{GH}$, Cortisol, prolactin

He3 concluded that preoperative and intra operative hemodilution is a part of a total approach to blood conservation and can be well tolerated to hematocrit ratios of $25 \%$ under a constant circulating normovolemic volume. It helps to reduce homologous blood transfusion by $18-90 \%$, improves nutritional blood flow and prevents thromboembolic complications. For maximum effectiveness in avoiding homologus transfusion. It should be combined with autologous blood predeposit, intraoperative scavenging and post operative autologous retransfusion.

Studied the mechanism of systemic vasodilatation during normovolemic hemodilution ${ }^{4}$. They concluded that neural reflexes do not modulate systemic vascular response to hemodilution. The systemic vasodilatation response to hemodilution is abolished after inhibition of endogenic NO synthatase. The decided NO (EDRF) is the most likely cause of systemic vasodilatation in $\mathrm{ANH}$.

In a prospective study5, 60 patients posted for $\mathrm{CABG}$ on $\mathrm{CPB}$ were assigned into two groups of 30 each. Group A: Combination of ANH with retrograde autologous priming $3(n=30)$ and Group $\mathrm{B}$ : Control. Patients who had a history of previous 
cardiac surgery and patients with severe left ventricular dysfunction were excluded.

They concluded retrograde autologous priming in combination with ANH significantly reduces the need for bank blood.

Goodnough et $\mathrm{al}^{7}$ performed moderate ANH for total hip replacement and found no significant change in the heart rate. Our patients results is in concurrence with their study. Hillel laks et $\mathrm{al}^{2}$ found statistically no significant change in blood pressures. There are many studies to recommend safe hemodynamic profile of $\mathrm{ANH}^{1,3,4}$.

\section{Conclusion}

ANH is safe, cheaper and effective method in replacing homologous blood transfusion for major elective orthopaedic surgeries. It can be easily performed with routine basic monitoring. The technical difficulties and the complications related to the procedure are very minimal when compared with the benefits.

\section{References}

1. Salma Mashragni Zafar et al, Indian Journal of Anesthesia (41) 166-1997

2. Atallah, Mohamed M, MD et al Does timing of hemodilution influence the stress response and overall outcome. Anesthesia and Analgesia, January 1993, vol 76, number1.

3. Eike martin MD,Ernil Hansen MD et al. acute limited normovolemicm hemodilution, Amethod for avoiding homologous transfusion. World journal of surgery 11,5359, 1987.

4. Doss, Doss N, MD, Ferrario Carlis m, MD, et al Mechanism of systemic vasodilation during Acute normovolemic hemodilution, Anesthesia and analgesia, July 1995, vol 81,no1.

5. K. Srinivas, MD, RK Kalyan singh, MD et al. (2001) combination of autologous transfusion and retrograde autologous priming decreases blood requirements.
Annals of cardiac Anesthesia 2001, 4(1)2832.

6. Mortel mans yyes J, MD et al, Effects of $6 \%$ HES and $3 \%$ modified fluid gelatin on intravascular volume and coagulation during intraoperative hemodilution. 